PREPARED FOR THE U.S. DEPARTMENT OF ENERGY, UNDER CONTRACT DE-AC02-76CH03073

PPPL-3973

PPPL-3973

UC-70

Observations of Anisotropic Ion Temperature in the NSTX Edge during RF Heating

by

T.M. Biewer, R.E. Bell, P.M. Ryan, and J.R. Wilson

June 2004

NM|

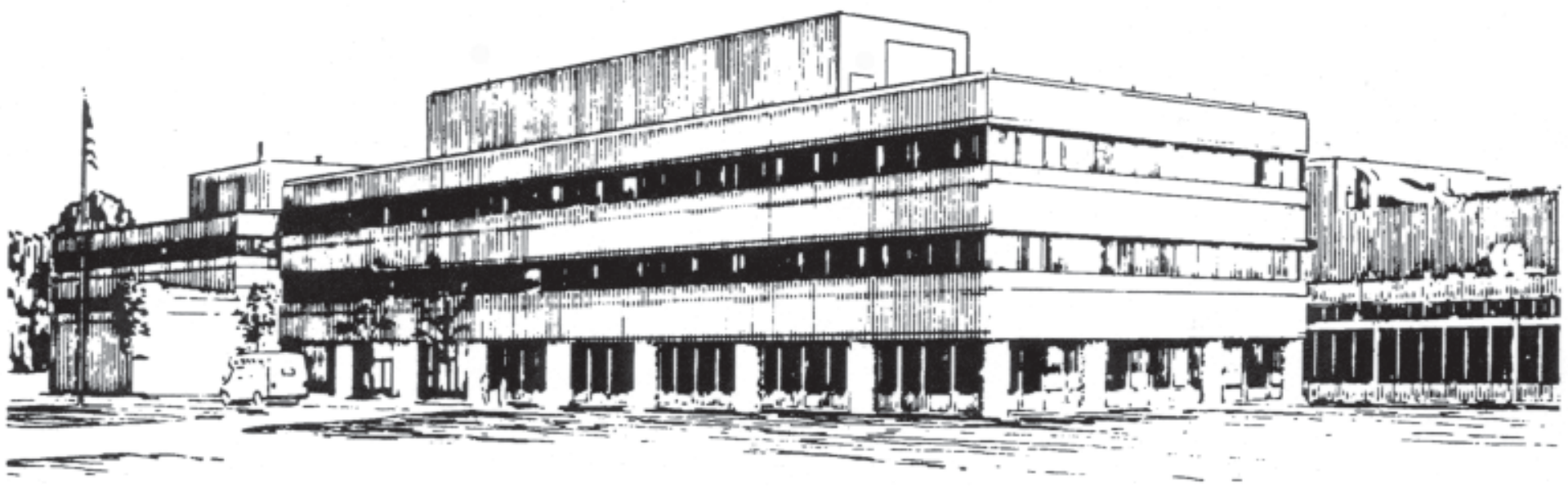

PRINCETON PLASMA PHYSICS LABORATORY PRINCETON UNIVERSITY, PRINCETON, NEW JERSEY 


\section{PPPL Reports Disclaimer}

This report was prepared as an account of work sponsored by an agency of the United States Government. Neither the United States Government nor any agency thereof, nor any of their employees, makes any warranty, express or implied, or assumes any legal liability or responsibility for the accuracy, completeness, or usefulness of any information, apparatus, product, or process disclosed, or represents that its use would not infringe privately owned rights. Reference herein to any specific commercial product, process, or service by trade name, trademark, manufacturer, or otherwise, does not necessarily constitute or imply its endorsement, recommendation, or favoring by the United States Government or any agency thereof. The views and opinions of authors expressed herein do not necessarily state or reflect those of the United States Government or any agency thereof.

\section{Availability}

This report is posted on the U.S. Department of Energy's Princeton Plasma Physics Laboratory Publications and Reports web site in Fiscal Year 2004. The home page for PPPL Reports and Publications is: http://www.pppl.gov/pub_report/

DOE and DOE Contractors can obtain copies of this report from:

U.S. Department of Energy

Office of Scientific and Technical Information

DOE Technical Information Services (DTIS)

P.O. Box 62

Oak Ridge, TN 37831

Telephone: (865) 576-8401

Fax: (865) 576-5728

Email: reports@adonis.osti.gov

This report is available to the general public from:

National Technical Information Service

U.S. Department of Commerce

5285 Port Royal Road

Springfield, VA 22161

Telephone: $1-800-553-6847$ or

(703) $605-6000$

Fax: (703) 321-8547

Internet: http://www.ntis.gov/ordering.htm 


\title{
Observations of Anisotropic Ion Temperature in the NSTX Edge during RF Heating
}

\author{
$\underline{\text { T. M. Biewer }}^{1}$, R. E. Bell ${ }^{1}$, P. M. Ryan ${ }^{2}$, and J. R. Wilson ${ }^{1}$ \\ 1. Princeton Plasma Physics Laboratory, Princeton, NJ 0854, USA
}

2. Oak Ridge National Laboratory, Oak Ridge, TN 37831, USA

A new spectroscopic diagnostic with both toroidal and poloidal views has been implemented in the edge of the National Spherical Torus Experiment (NSTX) ${ }^{1}$. This edge rotation diagnostic (ERD) $)^{2}$ was designed to measure the velocity and temperature of ions. The intersection of the diagnostic sightlines with the intrinsic emission shell provides the localization of the measurement. There are 7 toroidally directed views and 6 poloidally directed views of the outboard plasma edge. The poloidal view is $\sim 20 \mathrm{~cm}$ (toroidally) from the RF antenna, and the toroidal view is $\sim 2 \mathrm{~m}$ away. The sightlines are nearly tangent to the flux surfaces. The $\mathrm{C}^{2+}$ triplet near $4651 \AA$ and the $\mathrm{He}^{+}$line at $4685 \AA$ are measured. In the results presented here, helium is the bulk, "working" ion of the discharge.

The NSTX is a large spherical tokamak ${ }^{3}$ with a major radius of $0.85 \mathrm{~m}$ and a minor radius of $0.65 \mathrm{~m}$. The outer walls and center-stack are lined with protective carbon tiles. Pulse lengths for these NSTX discharges are $\sim 600 \mathrm{~ms}$, with an on-axis toroidal magnetic field of $\sim 0.3 \mathrm{~T}$. The plasma current is $500 \mathrm{kA}$. The on-axis electron temperature and density are $\leq 2 \mathrm{keV}$ and $\sim 2 \times 10^{19} \mathrm{~m}^{-3}$, respectively with $\leq 4.3 \mathrm{MW}$ of High Harmonic Fast Wave (HHFW) Radio Frequency (RF) auxiliary heating. ${ }^{4}$

\section{Observations}

During the application of $30 \mathrm{MHz}$ RF power, phased to drive current at a wave number of $7 \mathrm{~m}^{-1}$, distortions to the spectra of both $\mathrm{He}^{+}$(as shown in Fig. 1) and $\mathrm{C}^{2+}$ are observed. The distortion is more pronounced in the poloidal view, which is nearer to the antenna, but it is also present in the toroidal view. Under the influence of RF power, the spectra are clearly non-Maxwellian. Fitting the spectra with two Gaussians yields a very accurate representation of the measured data, suggesting that "hot" and "cold" thermal components are present in the distribution. Spatially inverting the data indicates that both populations reside at the same radial location, within a few $\mathrm{cm}$ of the plasma edge. The ionization potential of $\mathrm{He}^{+}$ions is $\sim 54 \mathrm{eV}{ }^{5}$ Hence a reasonable ion temperature for $\mathrm{He}^{+}$ intrinsic emission is on that order. The hot and cold helium poloidal temperatures at the highest RF input power are $\sim 500 \mathrm{eV}$ and $\sim 50 \mathrm{eV}$. Fig. 2 shows how the ion temperature and 
velocity of the hot and cold components vary with the amount of RF power that is applied to the plasma.
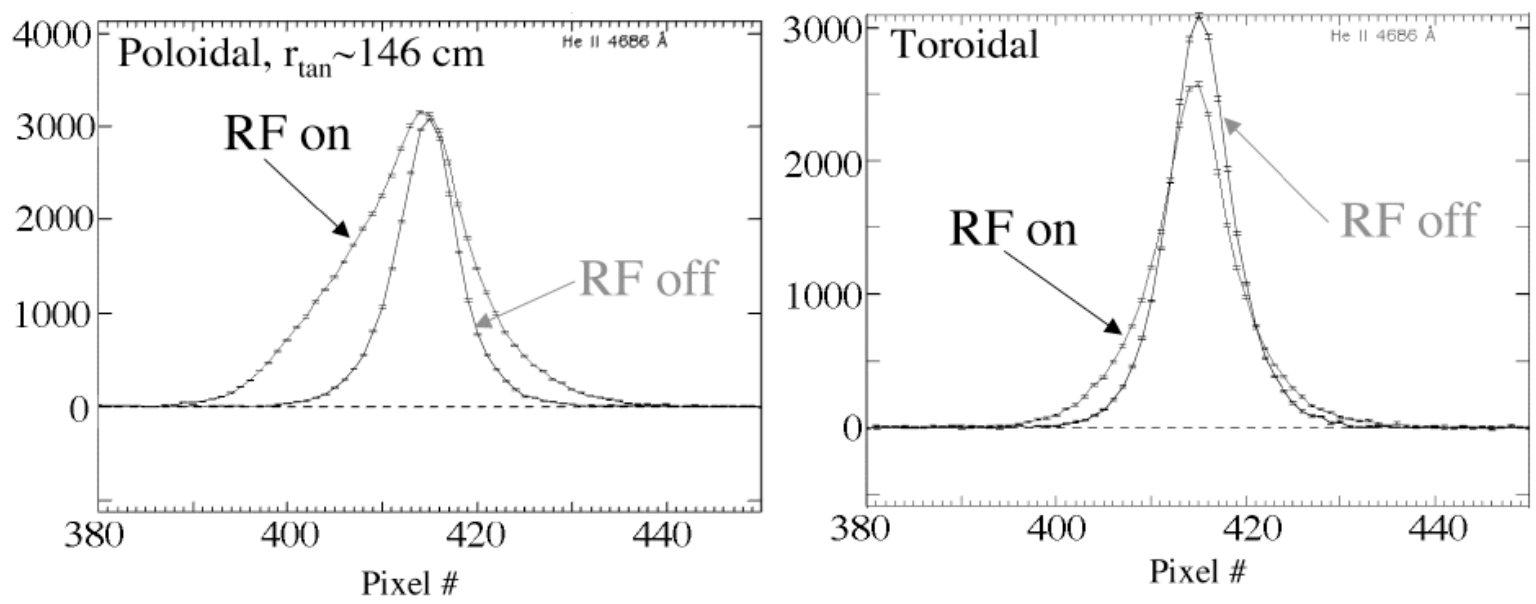

Figure 1: He spectra, fit with two Gaussians, from Shot 110144 during adjacent 10 ms time slices showing the difference in the (a) poloidal view and (b) toroidal view when HHFW RF power is applied.
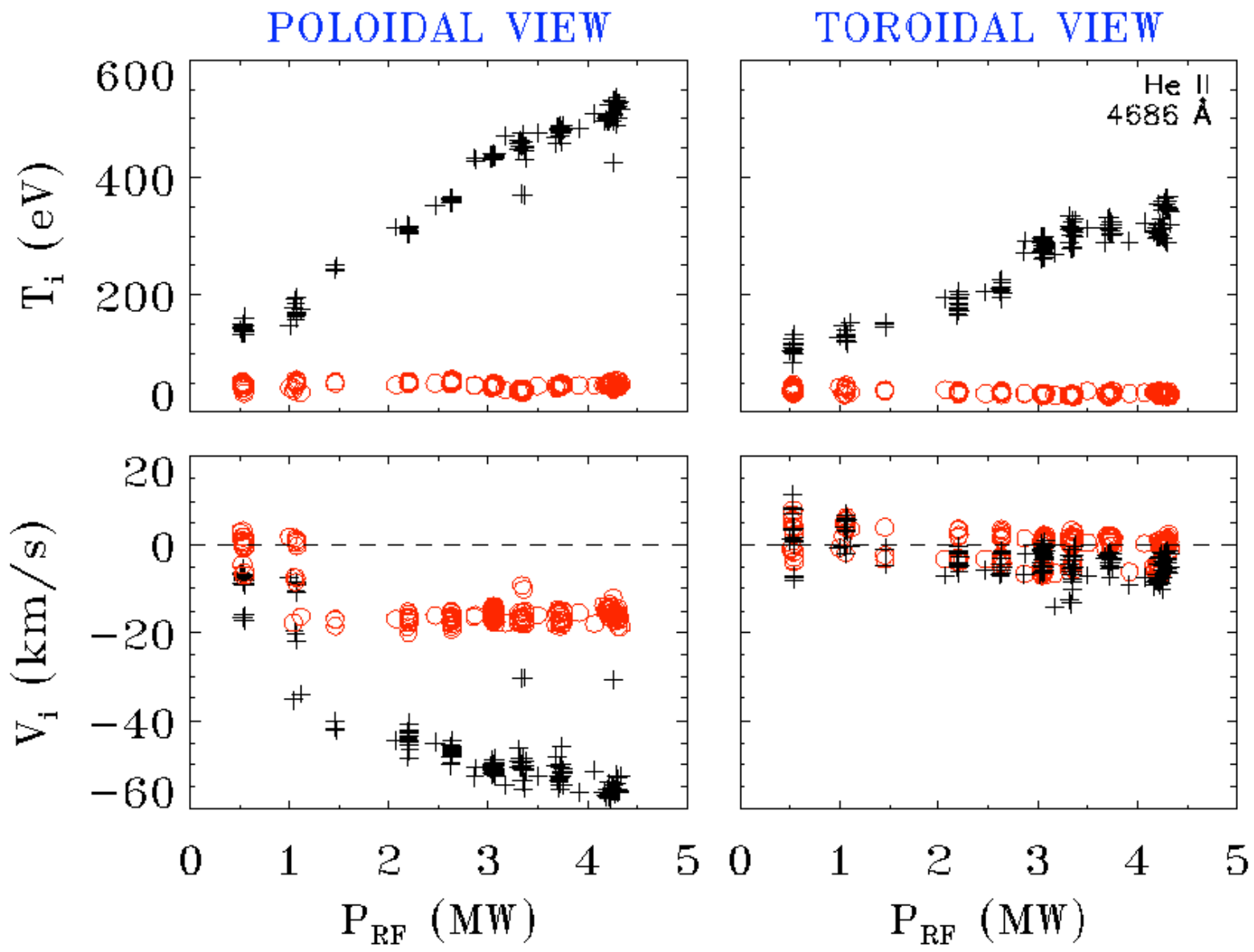

Figure 2: The temperature of the hot component (crosses) scales with $P_{R F}$, whereas the temperature of the cold component (open circles) is not strongly affected by the amount of RF power applied to the plasma. He $e^{+}$data from Shots 110133-110145 are shown. 
It is noteworthy that the poloidally and toroidally measured hot components do not have the same ion temperature for a given RF input power. The observed anisotropic temperature is consistent with hot ions having a larger perpendicular energy content. Since the magnetic field lines in the edge of NSTX have a pitch angle of $\sim 28^{\circ}$ (as calculated by EFIT equilibrium reconstructions ${ }^{6}$ ), the poloidal and toroidal ERD views are each sensitive to both the parallel and perpendicular ion velocity distributions. At this $B$-field pitch angle, the poloidal view is more sensitive to the perpendicular velocity distribution. Indeed, the ratio of the poloidal and toroidal temperatures of the hot $\mathrm{He}^{+}$is approximately equal to the tangent of the $B$-field pitch angle.

\section{Discussion}

The observation of the hot ion component is well correlated to the application of RF power, and the hot ion temperature scales with RF power. The presence of two apparently disparate populations of $\mathrm{He}^{+}$ions can be reconciled by the time scales of relevant processes. The time scale for ionization is $\sim 100 \mu \mathrm{s}$. However the emission time scale is $\sim 1 \mathrm{ns,}$ implying that light from both populations (hot and cold) would be readily observed, particularly since the time scale for thermalization between two populations of helium ions (at 50 and $500 \mathrm{eV}$ ) is $\sim 10 \mathrm{~ms}$. These time scales allow for the observation of the hot $\mathrm{He}^{+}$and hot $\mathrm{C}^{2+}$ transient states, which are observed then promptly ionized. Interpretation of the heating mechanism is more difficult, since it must account for both $\mathrm{He}^{+}$and $\mathrm{C}^{2+}$ heating.

The HHFW launched by the NSTX antenna was not expected to heat edge ions, though the expected core electron heating was observed. ${ }^{7}$ Resonant heating at the ion cyclotron frequency $\left(27^{\text {th }}\right.$ sub-harmonic of the launched HHFW for helium, and $41^{\text {st }}$ for carbon) is unlikely. One possibility for edge ion heating is parametric decay of the launched HHFW into an Ion Bernstein Wave (IBW) and an ion cyclotron quasi-mode (ICQM) ${ }^{8}$ IBW heating occurs in the perpendicular ion distribution, consistent with the observations of anisotropic temperatures. Nonlinear three-wave coupling provides a conversion mechanism for the HHFW into the IBW. Simulations of IBW propagation indicate that all of the IBW power would be absorbed in the outer $10 \mathrm{~cm}$ of the plasma, predominantly by fully stripped ions $\left(\mathrm{He}^{2+}\right.$ or $\mathrm{C}^{6+}$ ), though power would also be absorbed by non-fully stripped ions (e.g. $\left.\mathrm{C}^{2+}\right)$. Measurements made with a Langmuir probe for power levels in excess of $500 \mathrm{~kW}$ show side-bands of the pump HHFW, which are consistent with IBW's.

The observed hot ions could be due to charge exchange or recombination or ionization, or some combination of these. One possibility is that the two components of the 
distribution of $\mathrm{He}^{+}$ions are due to intrinsic emission of $\mathrm{He}^{+}$ions (cold component) and to emission of formerly fully stripped $\mathrm{He}^{2+}$ ions (hot component), which have undergone charge exchange with neutral atoms. If the antenna is sourcing atoms, this influx of neutral carbon, among other atoms, could charge exchange with the hot, fully stripped $\mathrm{He}^{2+}$ plasma ions, rendering them observable to the diagnostic. Whereas the cold component maintains an ion temperature that is on the same order as the ionization potential of $\mathrm{He}^{+}$, the hot component could be indicative of the ion temperature of fully stripped $\mathrm{He}^{2+}$ in the edge of the plasma, which has been heated by the IBW. Heating of solely the fully stripped ions would not immediately account for the observed, elevated $\mathrm{C}^{2+}$ ion temperatures, however. Multiple charge exchange interactions between antenna sourced neutrals and fully striped $\mathrm{C}^{6+}$ plasma ions to account for the hot component of $\mathrm{C}^{2+}$ emission would be unlikely. A more direct heating of the $\mathrm{C}^{2+}$ would be expected, perhaps from IBW's. Alternatively, the observed hot $\mathrm{C}^{2+}$ and $\mathrm{He}^{+}$could result from ionization and excitation of carbon and helium as they are heated by the RF waves. The induced IBW would have to pass radially through the $\mathrm{C}^{2+}$ shell (possibly depositing energy) before reaching and absorbing on the $\mathrm{He}^{+}$ions.

In summary, edge ion heating is observed when HHFW RF power is applied to NSTX plasmas. Parametric decay of the HHFW into an IBW is a possible candidate for the heating mechanism. Details of the heating mechanism are the subject of ongoing investigations.

\section{Acknowledgements}

The authors wish to recognize the many contributions of the NSTX group and collaborators at Oak Ridge National Lab. Thanks also to Steve Sabbagh of Columbia University for providing the EFIT reconstructions. This research was supported by the U.S. D.O.E. under contract: DE-AC02-76CH03073.

\footnotetext{
${ }^{1}$ J. Spitzer, M. Ono, et al., Fusion Technology 30, 1337 (1996).

${ }^{2}$ T. M. Biewer, R. E. Bell, et al., Rev. Sci. Instrum., 75, 650 (2004).

${ }^{3}$ Y.-K. Peng and D. Strickler, Nuclear Fusion 26, 769 (1986).

${ }^{4}$ M. Ono, Phys. Plasmas 2, 4075 (1995).

${ }^{5}$ A.R. Striganov and N. S. Sventitskii, Tables of Spectral Lines of Neutral and Ionized Atoms. (Plenum Press, 1968).

${ }^{6}$ L. L. Lao, H. S. John, et al., Nuclear Fusion 25, 1611 (1985).

${ }^{7}$ R. Majeski, J. Menard, et al., Radio Frequency Power in Plasmas-13 $3^{\text {th }}$ Topical Conference, Annapolis, MD (AIP Press, New York, 1999), p. 296.

${ }^{8}$ M. Porkolab, Eng. Fusion and Design 12, 93 (1990).
} 


\section{External Distribution}

Plasma Research Laboratory, Australian National University, Australia

Professor I.R. Jones, Flinders University, Australia

Professor João Canalle, Instituto de Fisica DEQ/IF - UERJ, Brazil

Mr. Gerson O. Ludwig, Instituto Nacional de Pesquisas, Brazil

Dr. P.H. Sakanaka, Instituto Fisica, Brazil

The Librarian, Culham Laboratory, England

Mrs. S.A. Hutchinson, JET Library, England

Professor M.N. Bussac, Ecole Polytechnique, France

Librarian, Max-Planck-Institut für Plasmaphysik, Germany

Jolan Moldvai, Reports Library, Hungarian Academy of Sciences, Central Research Institute for Physics, Hungary

Dr. P. Kaw, Institute for Plasma Research, India

Ms. P.J. Pathak, Librarian, Institute for Plasma Research, India

Ms. Clelia De Palo, Associazione EURATOM-ENEA, Italy

Dr. G. Grosso, Instituto di Fisica del Plasma, Italy

Librarian, Naka Fusion Research Establishment, JAERI, Japan

Library, Laboratory for Complex Energy Processes, Institute for Advanced Study, Kyoto University, Japan

Research Information Center, National Institute for Fusion Science, Japan

Dr. O. Mitarai, Kyushu Tokai University, Japan

Dr. Jiangang Li, Institute of Plasma Physics, Chinese Academy of Sciences, People's Republic of China

Professor Yuping Huo, School of Physical Science and Technology, People's Republic of China

Library, Academia Sinica, Institute of Plasma Physics, People's Republic of China

Librarian, Institute of Physics, Chinese Academy of Sciences, People's Republic of China

Dr. S. Mirnov, TRINITI, Troitsk, Russian Federation, Russia

Dr. V.S. Strelkov, Kurchatov Institute, Russian Federation, Russia

Professor Peter Lukac, Katedra Fyziky Plazmy MFF UK, Mlynska dolina F-2, Komenskeho Univerzita, SK-842 15 Bratislava, Slovakia

Dr. G.S. Lee, Korea Basic Science Institute, South Korea

Institute for Plasma Research, University of Maryland, USA

Librarian, Fusion Energy Division, Oak Ridge National Laboratory, USA

Librarian, Institute of Fusion Studies, University of Texas, USA

Librarian, Magnetic Fusion Program, Lawrence Livermore National Laboratory, USA

Library, General Atomics, USA

Plasma Physics Group, Fusion Energy Research Program, University of California at San Diego, USA

Plasma Physics Library, Columbia University, USA

Alkesh Punjabi, Center for Fusion Research and Training, Hampton University, USA

Dr. W.M. Stacey, Fusion Research Center, Georgia Institute of Technology, USA

Dr. John Willis, U.S. Department of Energy, Office of Fusion Energy Sciences, USA

Mr. Paul H. Wright, Indianapolis, Indiana, USA 
The Princeton Plasma Physics Laboratory is operated by Princeton University under contract with the U.S. Department of Energy.

\author{
Information Services \\ Princeton Plasma Physics Laboratory \\ P.O. Box 451 \\ Princeton, NJ 08543
}

Phone: 609-243-2750

Fax: 609-243-2751

e-mail: pppl_info@pppl.gov

Internet Address: http://www.pppl.gov 